Therapeutics

\section{Paracetamol as first line for treatment of knee and hip osteoarthritis}

\author{
10.1136/bmjebm-2019-111213
}

Check for updates

Igho J Onakpoya

Department of Primary Care, University of Oxford, Oxford, UK

Correspondence to: Dr Igho J Onakpoya, Nuffield Department of Primary Care Health Sciences, University of Oxford, Oxford OX2 6GG, UK; igho.onakpoya@phc.ox.ac.uk

Although several clinical guidelines recommend paracetamol as a first-line agent in the management of knee and hip osteoarthritis, the authors of a recently published Cochrane review called for a review of this recommendation.

Paracetamol is widely used as a first-line treatment for symptom relief in patients with osteoarthritis (OA). It is usually preferred to nonsteroidal anti-inflammatory drugs because of its better harms profile, especially in people at risk of gastrointestinal bleeding.

In a recent Cochrane review, ${ }^{1}$ the authors compared the effectiveness of paracetamol versus placebo in the management of knee or hip 0A. They searched seven scientific databases for relevant studies, including randomised controlled trials of participants with hip or knee OA irrespective of the intensity or duration of symptoms. The main outcomes were pain intensity, physical function, quality of life, adverse events, serious adverse events, withdrawal because of adverse events and liver toxicity. They used minimal clinically important difference (MCID) to compare the effect between paracetamol and placebo-MCIDs are a patient-centred concept that represents the smallest improvement that a patient considers 'meaningful and worthwhile.'

\section{Statistically significant benefit versus clinical \\ importance}

The review included 10 trials with 3541 participants and reported that paracetamol did not result in clinically important improvements in pain: MCID 3\% (95\% CI: 1\% to 5\%); or physical function: MCID 3\% (95\% CI: $1 \%$ to $5 \%$ ). There were no data on quality of life and no statistically significant or clinically important differences found in rates of adverse events, serious adverse events, withdrawal because of adverse events and liver toxicity between paracetamol and placebo.

The quality of evidence for most outcomes including pain and physical function was high. The review results were consistent with those of a previous network meta-analysis (NMA) ${ }^{3}$ which concluded that there is no role for using paracetamol as monotherapy for treatment of OA. The results also support the conclusions of another NMA, which found paracetamol to be least efficacious agent for OA management. ${ }^{4}$

However, several caveats exist. The MCID used by the authors was based on those of a previous publication, ${ }^{5}$ who in turn based their estimates on the median MCID from four other prior publications. To my knowledge there is no evidence that the cut-off point of 0.9 or 1.0 on a 10 point scale ( 9 or 10 on a 100-point scale) for pain or physical function respectively has been validated for use in $\mathrm{OA}-\mathrm{a}$ recent study of patients with knee OA concluded that adjustment for confounders could facilitate the generalisation of the results. ${ }^{6}$ In addition, the

\section{EBM Verdict}

EBM Verdict on: Paracetamol versus placebo for knee and hip osteoarthritis. Cochrane Database Syst Rev 2019;2:CD013273.

- Until convincing high-quality evidence demonstrates safety and effectiveness of other agents over paracetamol, it should remain a first-line agent in management of knee or hip osteoarthritis.

Cochrane review did not report data on the proportion of participants who reported improvement in pain symptoms.

That paracetamol had statistically significant benefits for pain and physical function (despite not achieving MCID thresholds; see the online supplementary table 1), coupled with its good harms profile indicate the drug should not be jettisoned as one of the first-line treatments for managing pain in the management of $\mathrm{OA}$. Indeed, a recent large prospective study of elderly subjects $(n=5429)$ concluded that 'despite polypharmacy and polymorbidity', acetaminophen (paracetamol) remains a first-line analgesic for managing pain. ${ }^{7}$

Contributors IO conceived and wrote the manuscript.

Funding The authors have not declared a specific grant for this research from any funding agency in the public, commercial or not-for-profit sectors.

Competing interests IJO holds grant funding from the NIHR School of Primary Care Research (NIHR Evidence Synthesis working group Project No: 390). He is a contributor to Meyler's Side Effects of Drugs Annual (SEDA), where he reviews reports of adverse drug reactions attributed to antihelminthic drugs.

Patient consent for publication Not required.

Provenance and peer review Commissioned; internally peer reviewed.

( $)$ Author(s) (or their employer(s)) 2020. No commercial re-use. See rights and permissions. Published by BMJ.

To cite: Onakpoya IJ. BMJ Evidence-Based Medicine 2020;25:40.

ORCID iD

Igho J Onakpoya http://orcid.org/0000-0002-2420-0811

\section{References}

1. Leopoldino A0, Machado GC, Ferreira PH, et al. Paracetamol versus placebo for knee and hip osteoarthritis. Cochrane Database Syst Rev 2019;2:CD013273.

2. Copay AG, Subach BR, Glassman SD, et al. Understanding the minimum clinically important difference: a review of concepts and methods. Spine J 2007;7:541-6.

3. da Costa BR, Reichenbach S, Keller N, et al. Effectiveness of non-steroidal anti-inflammatory drugs for the treatment of pain in knee and hip osteoarthritis: a network meta-analysis. Lancet 2017;390:e21-e33.

4. Zhu X, Wu D, Sang L, et al. Comparative effectiveness of glucosamine, chondroitin, acetaminophen or celecoxib for the treatment of knee and/or hip osteoarthritis: a network meta-analysis. Clin Exp Rheumatol 2018;36:595-602.

5. Wandel S, Jüni P, Tendal B, et al. Effects of glucosamine, chondroitin, or placebo in patients with osteoarthritis of hip or knee: network metaanalysis. BMJ 2010;341:c4675.

6. Angst F, Benz T, Lehmann S, et al. Multidimensional minimal clinically important differences in knee osteoarthritis after comprehensive rehabilitation: a prospective evaluation from the Bad Zurzach Osteoarthritis Study. RMD Open 2018;4:e000685.

7. Girard P, Sourdet S, Cantet C, et al. Acetaminophen Safety: Risk of Mortality and Cardiovascular Events in Nursing Home Residents, a Prospective Study. J Am Geriatr Soc 2019. 